\title{
FILOSOFIA COMO "VISÃO DE MUNDO": SOBRE A CRÍTICA À METAFÍSICA NO JOVEM NIETZSCHE, À LUZ DE SUA RELAÇÃO COM A FILOSOFIA SCHOPENHAUERIANA ${ }^{1}$
}

Wander de Paula (UFES) ${ }^{2}$

wanderdepaula@gmail.com

Resumo: $O$ presente artigo tem por pretensão central discutir alguns aspectos fundamentais da crítica de Nietzsche à metafísica, já nas suas primeiras reflexões filosóficas. Para tanto, serão mobilizados alguns de seus principais argumentos contra o estabelecimento da vontade como coisa em si no pensamento de Arthur Schopenhauer, e, por conseguinte, contra o próprio estatuto da metafísica nesta filosofia, de tal modo que se possa demonstrar as soluções encontradas pelo próprio autor a favor da possibilidade da metafísica. $\mathrm{O}$ artigo conta ainda, desse modo, poder contribuir para as discussões em torno da relação entre reflexões privadas e textos publicados do filósofo alemão, na medida em que defende a tese de que a partir de uma análise da crítica à metafísica em suas anotações pessoais se pode compreender os germes da mudança de postura em relação à mesma em seus textos publicados.

Palavras-chave: Nietzsche; Schopenhauer; metafísica.

\section{INTRODUÇÃO}

Uma tese que, se não hegemônica, se tornou ao menos paradigmática no que concerne ao problema da coisa em si em Nietzsche é a de Maudemarie Clark (1994), segundo a

\footnotetext{
${ }^{1}$ Recebido: 09-10-2016/ Aceito: 10-11-2016/ Publicado on-line: 19-01-2017.

${ }^{2}$ Wander de Paula é Professor Adjunto da Universidade Federal do Espírito Santo, Vitória, ES, Brasil.
} 
qual o autor, após um primeiro período em que reflete ${ }^{3}$ e se utiliza da distinção "coisa em si" e "fenômeno" para a formulação de sua metafísica de artista, passa a não mais utilizá-la como base de sua filosofia, embora ainda não apresente uma crítica explícita à mesma - mas apenas a rejeita como uma mera questão teórica que não tem sentido em termos de nossa ação na vida. Esse cenário se altera no aforismo 16 de Para além de bem e mal, ocasião em que o autor trata do tema nos seguintes termos:

Ainda há ingênuos observadores de si mesmos que acreditam existir 'certezas imediatas'; por exemplo, 'eu penso', ou, como era superstição de Schopenhauer, 'eu quero': como se aqui o conhecimento apreendesse seu objeto puro e nu, como 'coisa em si', e nem de parte do sujeito nem de parte do objeto ocorresse uma falsificação. Repetirei mil vezes, porém, que 'certeza imediata', assim como 'conhecimento absoluto' e 'coisa em si', envolve uma contradictio in adjecto [...] $(\text { KSA 5, p. 29) })^{4}$.

O sentido da afirmação de que coisa em si é uma contradictio in adjecto vem sendo objeto de estudo de vários intérpretes, como Mattia Riccardi ${ }^{5}$, que defende que a crítica nietzscheana a Kant provém de uma concepção relacional de coisa: se a coisa em si, em oposição ao fenômeno, é o "objeto considerado com respeito às suas propriedades nãorelacionais", a noção de coisa em si é contraditória, uma vez que é impossível conceber alguma coisa a não ser a partir de

\footnotetext{
${ }^{3}$ Broese (2005) afirma que em 1865, como estudante em Bonn, Nietzsche passa a ver a distinção entre coisa em si e fenômeno como o ponto inicial para qualquer teoria filosófica séria.

${ }^{4}$ Pode-se levar em conta, de modo semelhante, a seguinte passagem de Crepúsculo dos ídolos ("Como o mundo verdadeiro se tornou finalmente fábula", 6): "abolimos o mundo verdadeiro: que mundo restou? $\mathrm{O}$ aparente, talvez? [...] Não! Com o mundo verdadeiro abolimos também o mundo aparente!". (KSA 6, p. 81).

${ }^{5}$ RICCARDI, M. Nietzsche's Critique of the Kant's Thing in Itself. NSt. 39 (2010), 333-351.
} 
suas propriedades, isto é, não há propriedades além das relacionais (cf. RICCARDI 2010, p. 342 e p. 346).

A crítica de Nietzsche à noção de coisa em si é, contudo, bastante mais antiga e remonta aos seus primeiros contatos com a obra de Schopenhauer ${ }^{6}$. Pretendo apresentar a tese de que a crítica tardia à distinção kantiana "coisa em si" e "fenômeno", à qual acabo de me remeter, encontra suas primeiras formulações ainda na segunda metade da década de 1860 - ou seja, cerca de 20 anos antes da publicação de Para além de bem e mal -, e pode ser vista em sua crítica à noção schopenhaueriana de vontade. Será possível, desse modo, indicar também as primeiras reformulações do estatuto da metafísica já nas obras do período de juventude, especialmente em Schopenhauer como educador.

A despeito de sua leitura de Emerson, em 1862, e Platão, em 1863, as palavras Philosophie (filosofia) e Philosoph (filósofo) só se tornam importantes nas anotações de $\mathrm{Ni}$ etzsche após o seu contato com a obra do filósofo de Danzig: "a descoberta de Schopenhauer", afirma Thomas Brobjer, "não somente mudou o modo de pensar de Nietzsche e o impeliu a uma direção filosófica em geral, mas também influenciou muito diretamente o seu pensamento, atitude e leitura” (cf. BROBJER 2003, p. 42 e p. 47).

Schopenhauer parece ser, de fato, uma das principais fontes da recepção da filosofia de Kant e muito de seu entendimento sobre o filósofo de Königsberg é conduzido a

\footnotetext{
${ }^{6}$ Vários são os autores lidos por Nietzsche e que lhe são caros, ao lado de Schopenhauer, nas discussões sobre o estatuto da coisa em si. Ainda que apenas a título de menção, deve-se destacar especialmente Afrikan Spir, Gustav Teichmüller e Otto Liebmann, mas também Kuno Fischer, Friedrich Ueberweg, Eugen Dühring, Alfons Bilharz, Maximilian Drossbach e Richard Avenarius.
} 
partir de uma perspectiva schopenhaueriana (idem, cf. p. 612 e p. 65-6). O recurso que será feito adiante ao conjunto de anotações "Zu Schopenhauer" ("Sobre Schopenhauer"), escritas pelo autor entre o fim de março e o início de abril de 1868, terá como intuito principal comprovar essa tese. Trata-se de um período em que o autor, conforme destaca o biógrafo Curt Paul Janz, via a carreira de catedrático em filologia como um destino inevitável, mas, a despeito disso, procurava enriquecer os seus estudos de filologia por meio da filosofia. Nesse intuito, Nietzsche empreende uma leitura renovada da obra capital de Friedrich Albert Lange, História do materialismo e crítica de seu significado no presente, e procura esclarecer, sobretudo, a sua relação com Schopenhauer (cf. JANZ 1987, Vol. I, p. 211) - o que ele faz, em parte, por meio da escrita desse curto comentário à obra do filósofo, no qual o autor se posiciona de maneira bastante crítica à leitura schopenhaueriana da filosofia de Kant, à sua concepção de vontade e ao seu sistema em geral.

Em uma conhecida carta de Nietzsche a Gersdorff, datada do fim de agosto de 1866, o filósofo apresenta algumas de suas principais impressões da leitura de Lange e de sua influência na visão de Schopenhauer:

Temos aqui, diante de nós, um kantiano e pesquisador da natureza do mais alto esclarecimento. O seu resultado é resumido nas três sentenças seguintes:

1) O mundo dos sentidos é o produto de nossa organização.

2) Nossos órgãos visíveis (corporais) são, de modo similar a todas as demais partes do mundo fenomênico, somente figuras de um objeto desconhecido.

3) Nossa real organização permanece a nós, por isso, desconhecida, precisamente como as coisas exteriores. Nós temos continuamente diante de nós somente o produto de ambas. 
De tal modo, a verdadeira essência das coisas, a coisa em si, nos é não somente desconhecida, mas também o conceito da mesma é nem mais nem menos que o último aborto de um objeto dependente de nossa organização, do qual nós não sabemos se possui algum significado fora da nossa experiência. Consequentemente, opina Lange, deixem os filósofos livres, pressupondo que eles doravante nos edificarão. A arte é livre, também na região dos conceitos. Quem quer refutar uma composição de Beethoven, quem quer apontar um erro na madona de Rafael?

Você percebe que, mesmo nesses pontos de vista críticos mais estritos, nos permanece o nosso Schopenhauer, ele se torna até mesmo quase mais importante. Se a filosofia é arte, então Haym também deve se curvar diante de Schopenhauer; se a filosofia deve edificar, então eu sequer conheço um filósofo que é mais edificado que o nosso Schopenhauer (KSB 2, p. 159-60).

O trecho da carta acima indica, em primeiro lugar e de um ponto de vista geral, como Lange se torna uma fonte primordial para a revisão do Kant recebido via Schopenhauer. Em segundo, dá mostras da adesão de Nietzsche ao agnosticismo de Lange e, por conseguinte, da sua não adesão à vontade schopenhaueriana como correlata da coisa em si kantiana. Por fim, e principalmente, apresenta a preocupação do autor em sintetizar Schopenhauer e Lange, por meio da ideia langeana da metafísica com fins edificantes.

Se a leitura de Lange altera sensivelmente o modo com que o jovem Nietzsche concebe a metafísica, como parece ser o caso, cabe-nos questionar quais são os reflexos desse novo ponto de vista em sua obra publicada. A primeira fase do pensamento de Nietzsche é tomada pela maioria absoluta da fortuna crítica como uma adesão completa - ou quase completa - à metafísica. Mas qual é o estatuto da concepção de metafísica no pensamento de juventude do autor? Em 
que medida as suas reflexões privadas contribuem ou deixam antever uma reformulação da noção de metafísica no interior de sua obra de juventude? Uma análise dos termos com que filósofo alemão critica a metafísica schopenhaueriana pode trazer bons indícios de como se dá tal processo já nos primeiros anos de suas reflexões filosóficas.

\section{2. "Zu SCHOPENHAUER": A CRÍTICA DE NiETZSCHE, EM 1868, AO ESTABELECIMENTO DA VONTADE COMO COISA EM SI NO PENSAMENTO DE SCHOPENHAUER}

Em meados de 1868, Nietzsche já estava decidido a dedicarse à profissão de catedrático universitário e fazia planos para cursos. Sua relação com a filologia, a despeito disso, foi afrouxando-se cada vez mais e em proporção direta ao interesse com que se ocupava com a filosofia. Esse momento é uma espécie de ponto culminante daquilo que Janz entende como uma espécie de viragem filosófica, ocorrida entre os anos de 1867 e 1868, período em que cumpria o serviço militar. É desse período uma série de pontos de vista que se manteriam ao longo de toda a produção de Nietzsche, tais como a crítica ao caráter científico da filologia (a nova geração de filólogos deveria se concentrar em fazer um balanço e assumir o grande legado do passado, e não servir de operários à ciência); a crítica ao historicismo alemão (a recorrência ao passado deveria se dar somente no intuito de buscar nele exemplos e modelos para o nosso tempo); a crítica do intelecto ${ }^{7}$; e a defesa de um aristocratismo do espíri-

\footnotetext{
${ }^{7}$ Em carta a Erwin Rohde de 3 de abril de 1868, Nietzsche escreve: "caro amigo [...]: o instinto é o melhor no intelecto" (KSB 2, p. 265).
} 
to e do culto do gênio (JANZ 1987, Vol. I, p. 199-201). Já nesse período, como nos informa Janz, Nietzsche já nutria uma espécie de instinto antimetafísico, impulsionado sobretudo pela leitura do Kant de Kuno Fischer e da releitura de Lange:

Aquele que tiver em vista o curso das respectivas investigações, principalmente das fisiológicas desde Kant, não pode ter qualquer dúvida de que aquelas fronteiras sejam averiguadas de modo seguro e infalível, de tal modo que, salvo os teólogos, alguns professores de filosofia e o vulgo, ninguém cria ilusões a esse respeito. $\mathrm{O}$ reino da metafísica, e com ele a província da verdade 'absoluta', tem sido necessariamente deixado de lado, juntamente com a poesia e a religião. Quem quer saber algo que trate de se contentar agora com uma consciente relatividade do saber - como, por exemplo, todos os renomados pesquisadores da natureza. A metafísica pertence, então, para alguns homens, à região das necessidades do espírito, é essencialmente edificação; é, por outro lado, arte, propriamente a arte da poesia conceitual; deve-se assegurar, entretanto, que a metafísica nem como religião e nem como arte tem algo a ver com o denominado 'verdadeiro ou ser em si' (Carta a Paul Deussen do fim de abril/início de maio de 1868. KSB 2, p. 269).

Já nesse contexto de nova orientação filosófica Nietzsche parece ter estabelecido para o seu pensamento a importância de Schopenhauer:

[Nietzsche, W.P.] [...] Veio a perceber [...], com toda clareza, que o momento libertador que Schopenhauer havia lhe proporcionado não dizia respeito aos seus dogmas, mas ao caráter espiritual de Schopenhauer: em sua veracidade, em seu valor para o pensar, em sua amplitude fora do comum e a força artística de seu estilo (JANZ op. cit., vol. I, p. 211).

E é em meio a tais reflexões que o autor redige, conforme mencionado anteriormente, um pequeno comentário à obra de Schopenhauer, sob a rubrica " $\mathrm{Zu}$ 
Schopenhauer" ${ }^{8}$. Desconsiderando a divisão entre uma anotação e outra, o texto é constituído de quatro partes e precedido por uma espécie de esboço do conteúdo do mesmo, na forma de proposições (57[51]). Nestas, Nietzsche já explicita que a base de suas principais críticas ao pensamento de Schopenhauer, tal como exposto em sua obra principal, reside no modo com que ele recebe e redefine a noção kantiana de coisa em si. A partir desse pressuposto, o autor analisa as principais contradições da filosofia schopenhaueriana. Passemos àquelas que parecem ser as mais decisivas, em seu ponto de vista.

Nietzsche destaca, na primeira parte do texto (57[52] e [54]), que a solução encontrada por Schopenhauer para o problema da coisa em si kantiana foi convertê-la (umsetzen) em uma forma semipictórica (halb bildliche Form), a vontade: sem fundamento (grundlos) e sem conhecimento (erkenntni$\beta l o s)$, ela se revela como mundo através do aparato de representação (Vorstellungsapparat). Embora o autor enalteça a gratidão de Schopenhauer para com Kant, considera o termo vontade por demais cunhado (schwergemünzt) e muito abrangente (viel umschließend); além disso, Schopenhauer não teria avançado um só passo em relação às categorias Kant, ao forjar tal termo como a "pedra filosofal" (Stein der Weisen) sempre buscada pelo pensamento filosófico. Ao fim da primeira seção, Nietzsche destaca que o objetivo de seu texto é apresentar a quintessência do sistema schopenhaueriano por meio de uma análise de sua própria pessoa: como

\footnotetext{
${ }^{8} \mathrm{KGW} \mathrm{I/4,} \mathrm{p.} \mathrm{418-30,} \mathrm{que} \mathrm{compreende} \mathrm{as} \mathrm{anotações} \mathrm{57[51]-[52],} \mathrm{57[54]-[55]} \mathrm{e} \mathrm{57[61],} \mathrm{Outono} \mathrm{de}$ 1867 até Início de 1868. Na edição BAW: p. 352-61.
} 
poderia uma pessoa com um sistema tão esburacado (durchlöchert), se pergunta o autor, chegar a tais pretensões?

Adiante, na segunda parte (57[55]), Nietzsche levanta quatro objeções ao pensamento de Schopenhauer, todas elas envolvendo o problema da coisa em si ou direcionadas ao mesmo. A primeira, e mais geral, é a de que Schopenhauer falha ao ir adiante da concepção kantiana de coisa em si e que a vontade nada mais seria, desse modo, que uma "mera categoria oculta" (nur eine versteckte Kategorie)". A segunda é a de que a vontade, que Schopenhauer coloca no lugar da coisa em si kantiana, só pôde ser criada a partir de uma intuição poética (poetische Intuition), uma vez que as tentativas de prova lógica não poderiam satisfazer nem a Schopenhauer e nem a nós, os leitores. A terceira, mais decisiva, é a de que os predicados atribuídos à vontade são por demais determinados, para algo que é impensável, por excelência (Schlechthin-Undenkbares); além de serem constituídos tão somente por oposição ao mundo da representação. Por fim, ainda mais decisiva é a quarta objeção: partindo de uma possível refutação às três primeiras objeções (a de que a coisa em si poderia, ainda assim, ser pensada como possibilidade, uma vez que na região da transcendência [Gebiet der Transscendez] tudo aquilo que veio a eclodir na mente de um filósofo é possível; desse modo, a coisa em si poderia ser pensada a partir da conexão de duas possibilidades, da qual ela seria o polo oposto, negativo - Nietzsche está se referin-

\footnotetext{
${ }^{9}$ Karl Schlechta indica que, embora Nietzsche mencione Friedrich Überweg (autor dos três volumes do Grundriss der Geschichte der Philosophie von Thales auf die Gegenwart, publicado em 1867) como a fonte da qual ele retira essa expressão, o autor o faz através da História do materialismo, de Lange. SCHLECHTA 2009, cf. p. 297, nota 22.
} 
do aqui à oposição entre coisa em si e fenômeno), Nietzsche afirma que o sistema schopenhaueriano se torna embaraçado (verstrickt) em suas mãos, pelo fato de que o mundo não se permite ser estruturado em um sistema, do modo tão confortável como Schopenhauer desejava. O próprio autor, afirma Nietzsche, irá reconhecer ao fim de sua vida que "o problema mais difícil da filosofia" também não fora resolvido pelo seu pensamento: a questão dos limites da individuação.

Essa última observação é o ensejo de Nietzsche para discutir, na terceira parte do texto (57[55]), algumas contradições do sistema schopenhaueriano, as quais podem ser divididas em dois movimentos argumentativos complementares. $\mathrm{O}$ primeiro diz respeito ao fato de que, segundo o autor, a coisa em si schopenhaueriana é constituída tão somente por uma lista de propriedades negativas advindas do mundo dos fenômenos (Erscheinungswelt) e, por esse motivo, ele se posiciona contra a ideia (apresentada por Schopenhauer no capítulo 22 do primeiro volume de $\mathrm{O}$ mundo como vontade e representação) de que ela não poderia ser afetada pela forma mais geral da cognição. Se a vontade jamais pode ser um objeto, questiona Nietzsche, como ela pode ser pensada objetivamente? $\mathrm{O}$ máximo que se poderia alcançar seria, segundo o autor, uma forma de objetividade aparente (scheinbare Objektivität), proveniente de um X totalmente obscuro e inconcebível (ein durchaus dunkles unfaßbares X), cujos predicados são retirados do mundo dos fenômenos. O segundo movimento argumentativo, em conexão com a constatação anterior acerca da fonte dos predicados da vontade, se dirige a uma crítica da ideia de unidade (Einheit) da 
vontade schopenhaueriana (e, por conseguinte, também de seu sistema). $\mathrm{O}$ autor teria, afirma Nietzsche, tentado prover de sentido tais predicados ao defini-los como completamente inconcebíveis e transcendentes, o que seria garantido pela unidade metafísica da vontade. Isso implicaria em uma impossibilidade de conhecê-los por meio de nosso intelecto. Schopenhauer, entretanto, faria uso dessa característica essencial da vontade somente na medida em que percebia contradições em seu sistema, uma vez que, em outros momentos, ele fez um uso não-transcendente dos predicados da vontade ${ }^{10}$. Isso evidenciaria, segundo Nietzsche, que tal ideia de unidade, assim como a de vontade, só poderia ter sido retirada do mundo dos fenômenos; enquanto o núcleo genuíno (eigentliche Kern), o transcendental, volatilizar-se-ia entre os predicados da coisa em si. Sob esse ponto de vista, Nietzsche retoma conclusivamente o movimento inicial de sua argumentação: unidade (Einheit), eternidade (Ewigkeit) e liberdade (Freiheit) nada mais seriam que características negativas da multiplicidade (Vielheit), da temporalidade (Zeitlichkeit) e da causalidade (Causalität) que caracterizam o mundo dos fenômenos.

Nietzsche trata, na quarta e última parte do ensaio sobre a filosofia schopenhaueriana (57[55] e [61]), do modo pelo qual a vontade aparece (erscheinen) ou, formulado de modo mais claro, do aparato de representação no qual ela surge. Schopenhauer apresenta o intelecto (o autor se refere aqui ao capítulo 22 do segundo volume de $\mathrm{O}$ mundo como

\footnotetext{
${ }^{10}$ Nietzsche está comparando aqui dois textos de Schopenhauer, especialmente: o capítulo 25 do segundo volume de $\mathrm{O}$ mundo como vontade e representação e os capítulos 22 e 23 do primeiro volume do mesmo.
} 
vontade e representação) como Mēchanē, instrumento da vontade, de tal modo que o cérebro se desenvolve em uma escala crescente de necessidade para cumprir exigências das manifestações da vontade. Schopenhauer concebe, assim, o eu cognoscente e consciente como terciário (tertiär), uma vez que ele pressupõe o organismo (Organismus) e este, por sua vez, pressupõe a vontade. Aqui há, para Nietzsche, nada mais que uma diferenciação entre níveis de manifestações da vontade, que correspondem a necessidades existenciais em escala crescente (steigernde Existenzbedürfnissen). $O$ intelecto (Intellekt) surgiria, então, para suprir tais necessidades. Essa concepção, no entanto, acarretaria, segundo Nietzsche, em colocar um mundo dos fenômenos na frente do mundo dos fenômenos, de tal modo que a formação do intelecto não manteria, na realidade, qualquer relação com a vontade, mas somente com o mundo dos fenômenos. Isso deixaria a pergunta pela origem do intelecto ainda em aberto, pois algo que surge tal como ele, de repente e sem mediação (plötzlich und unvermittelt), em uma esfera de atemporalidade (Zeitlosigkeit) e de ausência de espaço (Raumlosigkeit), não deve manter qualquer mediação da causalidade (ohne Vermittlung der Causalität): o que surge de tal "mundo não mundano" (entweltlichte Welt) só pode ser, seguindo os princípios schopenhauerianos - a coisa em si. Desse modo, argumenta Nietzsche, ou o intelecto é um predicado eternamente ligado à coisa em si, ou não há intelecto algum, pelo fato de que jamais foi possível que ele viesse à existência. Então, afirma o autor, já que o intelecto existe, não é possível que ele seja uma ferramenta do mundo dos fenômenos, "como quer Schopenhauer", mas ele deve ser a coi- 
sa em si. Aqui reside, tal como me parece, uma das principais críticas de Nietzsche à noção schopenhaueriana de intelecto: ele seria o sujeito transcendental que cria as representações e o mundo dos fenômenos e, ao mesmo tempo, seria um aparato fisiológico, o cérebro.

De tal forma, conclui Nietzsche, a coisa em si schopenhaueriana seria, ao mesmo tempo, o principium individuationis e o fundamento da necessidade, o que significa, para o autor, que ela é meramente o mundo ordinário (vorhandene Welt) e nada mais que isso. Se Schopenhauer tinha em mente encontrar o X de uma equação, os seus cálculos apenas resultaram que ele é igual a $\mathrm{X}$, o que significaria que o autor não o teria encontrado.

Como se pode perceber, o estabelecimento da vontade enquanto coisa em si na filosofia de Schopenhauer constitui um problema de grande relevância para a crítica de $\mathrm{Ni}$ etzsche, ainda no período em que era estudante em Leipzig.

\section{SOBRE A ORIGEM DE "ZU SCHOPENHAUER": OS PONTOS DE VISTA DE DOIS AUTORES FUNDAMENTAIS NA (RE)ELABORAÇÃO DO ESTATUTO DA METAFÍSICA NO JOVEM NiETZSCHE}

Sandro Barbera (1995), em um artigo clássico sobre a relação de Nietzsche com o pensamento de Schopenhauer (mais especificamente, nos tempos de estudante em Leipzig e de professor na Universidade da Basileia), aponta o ensaio de Rudolf Haym sobre o autor como a grande influência 
das anotações de Nietzsche acima apresentadas ${ }^{11}$. Segundo Barbera, Haym interpreta Schopenhauer a partir de uma crítica da linguagem (Kritik der Sprache), destacando o problemático estabelecimento do conceito de vontade como a coisa em si e o mau uso da palavra "vontade", que nada mais seria que a execução de uma "mera metáfora" (blosse Metapher ${ }^{12}$. Esse mau uso da linguagem, segundo Haym, teria conduzido Schopenhauer (ao se utilizar do conceito "vontade" no âmbito dos fenômenos naturais, a fim de substituir o conceito "força" [Kraft]) a uma forma de antropomorfismo ${ }^{13}$.

Quatro pontos da argumentação de Haym levantados por Barbera me parecem ter sido essenciais para o texto de Nietzsche. Haym considera, em primeiro lugar, que a teoria schopenhaueriana do "duplo conhecimento" (doppelte Erkenntnis) do corpo ${ }^{14}$ nada mais seria que uma forma de "in-

\footnotetext{
${ }^{11}$ Em carta à mãe e a irmã, de 9 de dezembro de 1865, Nietzsche inclui o ensaio "Schopenhauer und seine Philosophie", do mesmo ano, em uma lista de livros que ele desejava como presentes para o natal. Cf. KSB 2, p. 101. O texto é, diferente do indicado na carta de Nietzsche, do ano de 1864 e, na compilação dos ensaios do autor no ano de 1903, é intitulado apenas como "Arthur Schopenhauer".

${ }^{12}$ HAYM, R. Arthur Schopenhauer. In: Gesammelte Aufsätze, Berlin, 1903, p. 260, apud BARBERA 1995, p. 131.

13 "A permuta recíproca do conceito geral de poder e do conceito especial vontade, esse jogo enigmático com a palavra vontade - em ligação com o conceito enigmático de coisa em si - possibilita sozinho, por um lado, naturalizar a vontade humana e, com ela, toda a ética; por outro lado, antropomorfizar a natureza de modo fantástico-poético" (HAYM 1903, p. 260, apud BARBERA, 1995, p. 132). Essa mesma tendência, afirma Barbera, se repete em duas anotações de Nietzsche, uma do período de elaboração de $\mathrm{O}$ nascimento da tragédia e outra do período de elaboração do primeiro volume de Humano, demasiado humano. Cf.: 5[83], Setembro de 1870 - Janeiro de 1871, KSA 7, p. 115; e 23[27], Fim de 1876 - Verão de 1877, KSA 8, p. 413.

14 "[...] Cita Nietzsche, nos apontamentos de Leipzig, a passagem de O mundo como vontade e representação na qual a coisa em si é apresentada como um castelo, inacessível do exterior pelos meios que, com o intelecto, temos à nossa disposição. Na principal obra de Schopenhauer, uma tal imagem introduz a teoria do 'reconhecimento' ('doppelten Erkenntnis') do corpo que percepciona através de dois atos de conhecimento simultâneos e sem ligação causal, um 'interior' ('inneren') e um 'exterior' ('äußeren'); uma teoria que Schopenhauer assinala como o 'marco' ('Markstein') da sua Cont.
} 
tuição romântica" (romantischer Intuition), "como um salto mortal sobre as formas da sensibilidade e as categorias do intelecto" (BARBERA, 1995, p. 129-30). Em segundo, o estabelecimento do intelecto como cérebro e ferramenta da vontade (Werkzeug des Willens) nada mais seria que um "espúrio idealismo naturalista [unechten naturalistischen Idealismus]" (HAYM 1903, p. 282, apud BARBERA 1995, p. 130) do autor: "a pretensão de conciliar a filosofia transcendental de Kant com a fisiologia de Cabanis desemboca em um labirinto de contradições, e precisamente na indicação destas contradições torna-se evidente a proximidade entre Haym e Nietzsche" (BARBERA 1995, p. 130). Em terceiro, Haym trata do "círculo" (Cirkel) da filosofia de Schopenhauer: "a vontade pode criar representações somente através da individuação, da qual a necessidade mesma de conhecer depende, necessidade essa que justifica o surgimento do intelecto" (idem) ${ }^{15}$ :

\footnotetext{
filosofia e que permite precisamente essa entrada no castelo da coisa em si”. BARBERA 2010, p. 27. Esta é versão adaptada para o português, aos cuidados de Nuno Nabais, de outro texto de Barbera, que contém muitos elementos em comum com texto de 1995 supracitado: cf. BARBERA 1994. Trata-se aqui de um tema central na filosofia de Schopenhauer, o do papel do corpo. Este é, como se sabe, uma manifestação imediata da vontade (e, portanto, a forma mais privilegiada de se alcançar o seu conhecimento), mas é, ao mesmo tempo, o meio pelo qual nos relacionamos com o mundo exterior.

${ }^{15}$ Barbera está aqui se referindo a uma linhagem de pensadores, desde Eduard Zeller até Ernst Cassirer, que consideram esse o circulus vitiosus da filosofia de Schopenhauer: "nessa 'antinomia da nossa capacidade de conhecer', como Schopenhauer lhe chamou no capítulo 20 dos Complementos a $\mathrm{O}$ mundo como vontade e representação, manifesta-se de novo o duplo olhar sobre o mundo definido pela simultaneidade e que já tinha sido descoberto pela característica estrutura do 'reconhecimento' ('doppelten Erkenntnis'). E aqui tinha Schopenhauer falado da necessidade de complementar a concepção transcendental com uma concepção ideológica (no sentido dos ideólogos, sobretudo de Cabanis) e tinha censurado Kant por ter visto o intelecto como algo de imediato em vez de o ter submetido a uma análise genealógica, no sentido da psicologia. Esse aspecto da filosofia de Schopenhauer é conhecido na literatura secundária, desde Eduard Zeller a Ernest Cassirer, como o seu circulus vitiosus. No ano de 1903, Kuno Fischer resumiu assim a antinomia: 'Intelecto e cérebro são idênticos em Schopenhauer: relacionam-se como função e órgão. Tempo e espaço Cont.
} 
O conhecimento deve, portanto, se tornar necessário através da individuação: mas a individuação se torna possível, primeiramente, através de tempo e espaço, portanto, através das formas do conhecer! Nós somos jogados em um [...] círculo. Pois não é a vontade, mas, tomado precisamente, é o intelecto que produz, de acordo com essa visão, o intelecto (HAYM p. 282, apud BARBERA 1995, p. 130).

Por fim, Haym afirma que o caráter fundamental da filosofia de Schopenhauer consiste em uma "indecisão de princípios" (prinzipielle Unentschiedenheit) "entre a imanência e a transcendência da vontade em relação aos fenômenos". Daí a sua análise do pensamento do autor a partir de uma crítica da linguagem, conforme mencionado ${ }^{16}$.

Outro aspecto da leitura de Haym que parece ter influenciado fundamentalmente a visão de Nietzsche até o período de Schopenhauer como educador é o de analisar o sistema filosófico schopenhaueriano como uma expressão fiel da personalidade de seu autor, "de seu humor melancólico e de sua radical denegação da "prosa do mundo": "também para Nietzsche [...] a visão de mundo é a expressão imediata de uma personalidade, e como tal é, a despeito das contradições e lacunas, incontestável” (BARBERA 1995, p. 133). Como vimos anteriormente, esse é um dos pontos de vista centrais do texto de 1868 sobre Schopenhauer e que irão

estão apenas no cérebro. E este mesmo cérebro? Ele está, com todos os seus acessórios e todas as condições e pré-condições, no tempo e no espaço! Aqui anda a teoria de Schopenhauer num palpável circulus vitiosus [...]'. Antes de Zeller e Fischer, contudo, já Rudolf Seydel tinha levantado o problema, num artigo do ano de 1857, que Nietzsche muito provavelmente não conhecia. Seydel viu nesta 'grande contradição' da teoria de Schopenhauer o malogro da tentativa de conciliar o idealismo de Fichte com a filosofia natural de Schelling” (BARBERA 2010, p. 28-9).

16 "As contradições surgidas desta indecisão são superadas somente através de um uso ilegítimo da linguagem, que se manifesta preponderantemente na ambiguidade utilizada de modo não-crítico do conceito 'vontade': uma palavra que designa propriamente um estado de coisas psicológico é usada, em um momento, para substituir o conceito 'força' na área dos fenômenos naturais e, em outro, para designar o em si dos fenômenos em geral, a coisa em si” (BARBERA 1995, p. 130-1). 
culminar, segundo a tese que se defende no presente artigo, na Extemporânea sobre o filósofo de Danzig.

O resultado a que chega Haym em sua análise imanente da filosofia de Schopenhauer é a constatação de contradições insolúveis no sistema; a mesma constatação vale para o exame de suas credenciais críticas: Schopenhauer teria desvirtuado inteiramente a herança kantiana. $\mathrm{O}$ resultado dos dois primeiros níveis de abordagem da filosofia de Schopenhauer coloca o leitor diante de um verdadeiro enigma: como pôde um filósofo elaborar e se agarrar ao longo de toda uma vida a tal conjunto de inconsistências? A resposta encontrase no terceiro nível de análise, no exame da gênese da obra e de seu vínculo com a personalidade do autor. Haym introduz neste contexto uma tese geral sobre a natureza da obra filosófica que ele supõe aplicar-se paradigmaticamente ao caso de Schopenhauer: um sistema filosófico é antes de tudo expressão da personalidade e das convicções morais de seu autor. Poucas teses terão tido maior repercussão na compreensão nietzscheana da filosofia (LOPES 2008, p. 121-2. Grifos meus).

Rogério Lopes explica que Haym estava atendendo à demanda da "moda schopenhaueriana", que coincidiu com os últimos anos de vida do filósofo, da qual surgiram vários estudos biográficos de seus discípulos e que, em geral, apresentavam uma contradição entre a biografia do autor e sua doutrina filosófica. Haym, por sua vez, teria feito o movimento contrário, recorrendo à biografia do autor para conferir sentido à sua doutrina filosófica:

O êxito incontestável de Schopenhauer estaria justamente no fato de ter traduzido em uma visão de mundo, graças a seus méritos como estilista, o núcleo de seu caráter. Esta concessão que Haym faz ao talento de Schopenhauer como escritor encontrará ampla acolhida por parte de Nietzsche, que a utilizará como um dos pilares de sua terceira Consideração Extemporânea. Até onde é possível julgar sobre a questão, pode-se dizer que Haym fornece a Nietzsche a primeira indicação sobre o caráter confessional da filosofia, ao mesmo tempo 
em que estabelece um vínculo de dependência entre o valor filosófico deste gênero de memória involuntária e o mérito estilístico de um pensador [...]. O jovem Nietzsche dirá mais tarde, na Terceira Extemporânea, traduzindo esta última asserção em seu vocabulário próprio, que estes méritos bastam para nos assegurar de sua veracidade e honestidade intelectual. Nós poderíamos dizer ainda, recorrendo a uma formulação posterior de Nietzsche, que Schopenhauer cumpriu com êxito a mais árdua das tarefas filosóficas, a de conferir estilo à própria personalidade (idem, p. 122-3)

Se levássemos em conta, afirma Barbera, somente o ensaio de Haym e as anotações de Nietzsche do período de Leipzig, ficaríamos com a impressão de que o autor não teria feito nenhuma objeção às críticas de Haym a Schopenhauer, "ao ataque à metafísica da vontade e à equiparação da filosofia de Schopenhauer à expressão de uma arte poética de cunhagem romântica" (BARBERA 1995, p. 132-3). Assim seria se Nietzsche não tivesse sido mediado nessa discussão também por Lange:

Graças à mediação de Friedrich Albert Lange, Nietzsche pode, no entanto, atribuir um valor positivo e afirmativo, ao invés de um negativo e polêmico, à ideia fundamental de tal crítica. Na famosa carta a Gersdorff do fim de agosto de 1866, Nietzsche menciona que para Lange a irreconhecibilidade da coisa em si concede ao filósofo uma liberdade que se assemelha com aquela do artista: por isso é 'a arte [...] livre, também na região dos conceitos. [...] Você percebe que, mesmo sob esse mais rígido ponto de vista crítico, nos permanece o nosso Schopenhauer, quiçá ele se torna ainda mais importante. Se a filosofia é arte, então Haym também deve se curvar diante de Schopenhauer' (idem, p. 133) ${ }^{17}$.

\section{A leitura da obra capital de Lange sobre o materialismo}

\footnotetext{
${ }^{17} \mathrm{Na}$ sequência dessa carta, afirma ainda Nietzsche: "se a filosofia deve edificar, então não conheço ao menos um filósofo que mais edifique que o nosso Schopenhauer" (KSB 2, p. 160).
} 
parece ter sido, de fato, decisiva na compreensão e crítica de Nietzsche à metafísica, bem como a Schopenhauer. A tese de James Porter, e que me parece bastante plausível, é a de que seria impossível que o autor tivesse tomado de modo inocente a metafísica da vontade schopenhaueriana em O nascimento da tragédia, dados a sua apreciação de Lange e dos atomistas gregos - em especial Demócrito (ponto central, segundo Porter, de sua filologia entre 1867-69) -, e um posicionamento crítico em relação à metafísica que data, na verdade, desde o início da década de 1860, conforme atesta o autor por meio de uma carta de Nietzsche a Krug e Pinder de 27 de abril de 1862 (cf. PORTER 2000, p. 05 e 07) - na qual o autor critica a "ilusão de um mundo sobrenatural (überirdisch)" em oposição ao mundo terreno (irdisch), afirmando que "somente nós somos responsáveis por nós mesmos" (KSB 1, p. 201-2). O contato com a obra de Lange proporcionou a Nietzsche, segundo Porter, afirmar, em 1866, que nossas sensações internas e externas são igualmente "produtos de nossa organização" e, mais tarde, que "o conceito de uma coisa em si, separado de seu suporte conceitual nessa organização (que também é sua fonte), ameaça cair em uma pura falta de sentido" (PORTER p. 08; cf. KSB 2, p. 156-61 e KSA 7, p. 425):

Metafísica, Nietzsche reconhece desde cedo, é uma falsificação; mas ao mesmo tempo é um sintoma de necessidades assentadas profundamente (Gemüthsbedürfnisse). Metafísica pode ser uma mera construção que é valiosa para fins de edificação (Erbauung) e não pode ser mais que um tipo de poesia conceitual (Begriffsdichtung) [...]. Lange ofereceu a Nietzsche um modelo para confrontar o materialismo (que Lange considerou como um componente essencial da história da filosofia) com o kantismo, o instrumento moderno mais poderoso na crítica da metafísica tradicional [...]. Mas o que Lange ensina a 
Nietzsche, ainda que Lange possa estar simplesmente confirmando os próprios instintos filosóficos de Nietzsche, é não somente que a metafísica é um empreendimento fictício digno de ser esgotado de uma vez por todas, mas também que a sua ressurreição é uma necessidade inescapável e constitutiva implantada profundamente na natureza humana (idem, p. 08-9).

É a partir desse ponto de vista que Porter analisa o texto de Nietzsche de 1868 sobre Schopenhauer. Importante para o presente texto é uma de suas principais teses de leitura tanto das anotações de 1868 quanto de $\mathrm{O}$ nascimento da tragédia (mas que certamente não encerra qualquer originalidade), segundo a qual a vontade não é, para Nietzsche, o incontestável fundamento metafísico do universo: trata-se de um conceito em dependência última com a noção kantiana de coisa em si, por sua pretensão de existência absoluta e objetiva. É esse aspecto, segundo Porter, que leva Nietzsche a afirmar que a coisa em si seria, do mesmo modo em ambos autores, somente uma mera categoria oculta (idem, $\mathrm{p}$. 59) e que Schopenhauer deriva a sua coisa em si somente de suas aparências (idem, p. 62) ${ }^{18}$.

Instigante é, ainda, a ideia de Porter de que o texto de 1868 representa não somente uma refutação filosófica a Schopenhauer, mas o esboço da "memória inconsciente de um sistema filosófico", uma vez que, segundo a leitura de Nietzsche, o "sistema schopenhaueriano conhece e nega as suas próprias falhas, e ocasionalmente trai a si mesmo, como se ele fosse contra as suas próprias melhores intenções":

\footnotetext{
18 "É a contradição do mundo diante de nós como ele existe, não além de nós. Ainda melhor, a coisa em si é simplesmente a contradição de uma tentativa de construir esse mundo. E, finalmente, a coisa em si representa a impossibilidade de qualquer metafísica transcendental, bem como 'o impulso obscuro' que impele sujeitos à especulação metafísica, o que alhures é chamado em Schopenhauer uma 'necessidade metafísica'". Cf., também, p. 72-3.
} 
Atacando a estrutura lógica da vontade e a 'história' de sua evolução (sua estrutura de 'esquecimento'), Nietzsche pode tomar Schopenhauer simultaneamente de diversos ângulos. A sua crítica é mais que uma crítica filosófica; é uma interpretação imaginativa, em forma dramática, da filosofia de Schopenhauer e de suas fraquezas críticas imanentes (Idem, p. 69).

O benefício que o texto de Porter traz para a presente discussão reside, portanto, no fato de medir a importância da leitura de Lange por Nietzsche e apresentar como a sua concepção de metafísica é sensivelmente influenciada após o contato com tal obra, de tal forma que Nietzsche parece alterar a sua visão acerca do sistema filosófico de Schopenhauer, dando mais ênfase à metafísica enquanto fim edificante e preocupando-se menos com suas questões epistemológicas. Intensifica-se, simultaneamente, uma abordagem, influenciada sobretudo pela leitura de Haym, da personalidade do autor, tendência que parece encontrar o seu ápice, conforme mencionado, na publicação de Schopenhauer como educador.

Haym e Lange são, ao que tudo indica, as duas principais influências de Nietzsche em "Zu Schopenhauer". Enquanto Barbera parece dar preferência ao primeiro e Porter ao segundo, Lopes apresenta uma posição intermediária entre os comentadores - ainda que tenda a priorizar Lange -, procurando estabelecer em que medida o autor se vale das teses de ambos ${ }^{19}$. Lopes destaca que a leitura de Haym ocorreu entre janeiro e abril de 1866, portanto dois ou três meses antes da leitura de Lange, e que, embora Nietzsche

\footnotetext{
${ }^{19}$ Além de Haym e Lange, Lopes também considera a leitura do terceiro volume de Grundriss der Geschichte der Philosophie von Thales bis auf die Gegenwart (1866), de Friedrich Überweg, uma importante fonte de "Zu Schopenhauer" (LOPES 2008, cf. p. 91-3).
} 
tenha se aborrecido com o texto do primeiro, após o contato com o segundo "corroborou a tese de Haym da vulnerabilidade epistêmica da metafísica de Schopenhauer, mas ofereceu a ele simultaneamente um critério para justificar sua adesão a esta metafísica distinto do critério de confiabilidade epistêmica” (LOPES 2008, p. 88. Para uma análise minuciosa do texto de Haym: idem, cf. p. 95-126). E se Nietzsche, em um primeiro momento, "considerou a reforma do sistema schopenhaueriano em termos de reajuste conceitual e eliminação de contradições como um empreendimento supérfluo", e isto em função de sua crença de que a metafísica de Schopenhauer se enquadrava aos critérios propostos por Lange, em um segundo "reconhece que o filósofo teve inigualável êxito ao traduzir, com a ajuda de imagens e conceitos, os traços essenciais de sua personalidade em uma visão de mundo" (idem, p. 89), êxito esse possível graças ao talento literário de Schopenhauer.

A interpretação dos méritos do sistema schopenhaueriano à luz dos critérios de edificação propostos por Lange foi sem dúvida reforçada pelas objeções de Haym à pretensão de Schopenhauer de reivindicar para a sua metafísica um estatuto de verdade. Haym nega esta pretensão, mas confessa que a visão de mundo schopenhaueriana testemunha uma fantasia poética poderosa e abrangente. Nietzsche foi levado, por essas e outras vias, a acreditar que bastava medir a filosofia de Schopenhauer segundo sua capacidade de atender às necessidades subjetivas de consolo e edificação (Idem, p. 89-90).

Tal forma de considerar a filosofia de Schopenhauer impede que Nietzsche, destaca Lopes, se proponha a escrever uma apologia ou uma crítica do pensamento do autor, dado que "visões de mundo não podem ser refutadas através de razões; o valor de uma filosofia se mede pelos seus 
efeitos práticos; de resto seria desumano aniquilar crenças desta natureza" (Idem, p. 90; cf. KSB 2, p. 228-9 e p. 32730).

Se Nietzsche passa a considerar, conforme destacado anteriormente, a metafísica em função de seu valor edificante, não estaria o autor, questiona Lopes, se comprometendo conscientemente com a ilusão? "Supondo que isso seja factível do ponto de vista psicológico", acrescenta o autor, "seria defensável do ponto de vista de uma ética da vida filosófica?". Lopes entende ser essa a base da tensão que estará presente nas reflexões de Nietzsche nos póstumos do início da década de 70 e no restante de toda a produção do autor. Tal tensão estaria ancorada na tentativa de implementar o programa de Lange no início dos anos 70 (idem, cf. p. 158).

No que diz respeito ao texto 1868 sobre Schopenhauer, Lopes apresenta uma tese bastante clara: "entre o jovem $\mathrm{Ni}$ etzsche e o Nietzsche do período intermediário não há nenhuma diferença substantiva no que concerne ao estatuto epistêmico de hipóteses metafísicas". Tal tese vem apenas a corroborar aquilo que já foi apresentado anteriormente sobre o papel central de Lange na concepção nietzscheana de metafísica (agnosticismo, ficcionalismo generalizado, compromisso com a "moralidade intelectual" e idealismo prático; idem, cf. p. 126-7), o que Lopes entende, se utilizando da expressão de Langbehn, como uma "crítica defensiva", "destinada a criar um clima mais favorável à recepção de sua filosofia", com a pretensão de "eliminar do sistema schopenhaueriano o seu intuito dogmático" (idem, cf. p. 141-2). 
A partir da análise das anotações críticas de Nietzsche sobre a filosofia schopenhaueriana pôde-se demonstrar como o autor já possuía uma visão bastante crítica em relação à metafísica mesmo antes da publicação de $\mathrm{O}$ nascimento da tragédia, que muitas vezes é tomado - erroneamente, ao que tudo indica - como uma total adesão à metafísica e, ainda mais especialmente, à metafísica schopenhaueriana. Se em sua primeira obra essa crítica não se faz tão presente quanto nas anotações que lhe antecedem, os seus resultados teóricos podem ser percebidos em Schopenhauer como educador, nos termos que serão discutidos adiante.

\section{FILOSOFIA COMO "VISÃO DE MUNDO": CONSIDERAÇÕES SOBRE SCHOPENHAUER COMO EDUCADOR}

Nas anotações pessoais posteriores a 1868 Nietzsche desenvolve as críticas de "Zu Schopenhauer", de tal modo que se torna claro que o autor possui, antes mesmo de $\mathrm{O}$ nascimento da tragédia, uma terminologia bastante diversa daquela que identifica a vontade com a coisa em si, tal como ocorria no pensamento de Schopenhauer ${ }^{20}$. Essas discussões sobre

\footnotetext{
${ }^{20}$ Com isso, espera-se que ao menos indicar que, a despeito, por exemplo, da ambiguidade do uso dos termos Ur-Eine (Uno-Primordial) e Wille (vontade) em sua primeira publicação, Nietzsche não aceita ingênua e integralmente as credenciais teóricas schopenhauerianas em favor da metafísica nem mesmo na obra publicada, ainda que nela as críticas sejam, no mínimo, bem mais latentes. Isso caracterizaria o que Claudia Crawford denomina de "vida essencialmente dupla" de Nietzsche: por um lado, como o partidário wagneriano da filosofia de Schopenhauer que publica O nascimento da tragédia e o conjunto das Considerações extemporâneas e, por outro, como o filósofo cético e crítico que desenvolve privadamente uma posição bastante conflitante com aquela pública. No que diz respeito a Schopenhauer, sua posição é bastante clara: "Nietzsche foi um discípulo de Schopenhauer e, ainda, um crítico subterrâneo de Schopenhauer" (CRAWFORD 1988, p. 14). Não parece inteiramente plausível, contudo, levar adiante uma diferenciação como a proposta pela autora, uma vez que o filósofo reformula a sua posição acerca da metafísica mesmo na obra publicada de juventude, e não apenas com a publicação de Humano, demasiado humano, como quer boa parte da fortuna crítica. O texto de Crawford, por outro lado, nos permite perceber como Nietzsche possui uma terminologia substancialmente diversa daquela de Schopenhauer já nas anotações que antecedem a sua primeira Cont.
} 
o estatuto da coisa em si não são tão claras em sua primeira obra publicada quanto em nas anotações que lhe precedem, mas o tom em relação à metafísica se altera significativamente na terceira das Considerações extemporâneas, Schopenhauer como educador (doravante SE, nas citações). Neste texto se torna nítida uma nova abordagem da filosofia de Schopenhauer e, por conseguinte, de sua metafísica, que vinha sendo formulada, como vimos, desde a década de 1860. Esse processo pode ser percebido em três momentos fundamentais da obra.

O primeiro ocorre no capítulo 3, quando Nietzsche trata dos perigos em meio aos quais Schopenhauer cresceu: "isolamento" (Vereinsamung), "desespero da verdade" (Verzweiflung an der Wahrheit) e "petrificação na esfera moral ou intelectual" (Verhärtung, im Sittlichen oder im Intellectuel-

obra. A partir do estudo de anotações pessoais do autor dos anos de 1870 e 1871, por ela intitulada "Notas sobre Anschauung" (idem, cf. esp. p. 16 e p. 158-61), Crawford demonstra que o uso do termo Anschauung se torna central nesse movimento de revisão do pensamento schopenhaueriano. O que parece, contudo, ainda mais decisivo e que realmente fomenta o indício de que Nietzsche esteja se afastando de Schopenhauer é o uso que ele faz do termo Ur-Eine (uno primordial) em suas reflexões privadas. E, nesse sentido, o texto de Crawford é bastante elucidativo. A autora tem o mérito de apontar que, a despeito das flutuações de Nietzsche entre os conceitos de Ur-Eine e Wille (que em determinados momentos aparecem como semelhantes não apenas na obra publicada), o segundo pode ser entendido como atividade do primeiro: "ao construir a sua visão de mundo em Anschauung, Nietzsche está expressando ideias influenciadas pela filosofia do inconsciente de Hartmann. Nietzsche, entretanto, não usa a palavra inconsciente, mas adere aos termos schopenhauerianos vontade e representação. No entanto, Nietzsche usa a palavra vontade em conjunto com a palavra ser, como os dois aspectos do termo mais abrangente Ur-Eine. A vontade é a atividade do Ur-Eine, enquanto o ser é o aspecto eterno, imutável do Ur-Eine. Nietzsche usa o termo representação de duas formas nas 'Notas sobre Anschauung'; em primeiro lugar como a representação (mecanismo) que pertence à atividade da vontade em sua atividade de projeção de imagens, e em um segundo sentido similar à representação de Schopenhauer, como a projeção consciente de imagens da inteligência humana. E Nietzsche insere uma dimensão entre vontade e representação que ele chama aparência (Erscheinung)" (ibidem, p. 161). Crawford cria, a partir desse ponto de vista, um esquema explicativo no qual o Ur-Eine compreende a vontade e o ser, em um primeiro plano, e a representação em um segundo, sendo tais planos intermediados pela aparência. Esse esquema é bastante próximo, segundo a autora, ao modo pelo qual Hartmann entende o inconsciente (ibidem, cf. p. 161). É a partir desse ponto de vista que se pode pensar no jovem Nietzsche, por exemplo, uma apologia da ilusão e, principalmente, uma concepção de vontade não enquanto coisa em si, tal como em Schopenhauer, mas enquanto a "forma mais geral da aparência" (allgemeinste Erscheinungsform), como escreve Nietzsche em uma de suas célebres anotações (7[165], Fim de 1870 - Abril de 1871. KSA 7, p. 202). 
len). Ao tratar do segundo deles, o autor retoma a influência kantiana na filosofia de Schopenhauer, mas sobretudo o seu afastamento da mesma, ao considerar o homem como sofrimento (Leiden) e desejo (Begehren) e não como uma "barulhenta máquina de pensar e calcular" (klappernde Denkund RechenMaschine). O filósofo se torna para nós, desse modo,

[...] O líder que nos conduz da caverna da obscuridade cética ou da renúncia crítica às alturas da consideração trágica, ao céu noturno e suas estrelas infinitamente sobre nós, e ele mesmo como o primeiro que tomou esse caminho. A sua grandeza reside em ter colocado diante dele uma pintura da vida como um todo, no intuito de interpretá-la como um todo; enquanto as mais perspicazes cabeças não podem se libertar do erro de que se aproxima com essa interpretação, se alguém minuciosamente investigar as cores com as quais essa pintura [Bild] é produzida e o material sobre o qual é pintada; talvez com o resultado alguém conclua que a tela é tecida de tal modo intrincado e com tais cores que é quimicamente inexplicável (SE, 3. KSA 1, p. 356. Grifos meus).

Esse é o argumento de Nietzsche a favor do modo com que a filosofia schopenhaueriana considera a existência: somente como um todo. O benefício dessa forma de pensamento residiria no fato de que, ao ler a sua própria vida, o indivíduo poderia compreender os "hieróglifos da vida universal" (Idem, p. 357). A discussão de Nietzsche nesse momento é com a pretensão científica - aqui atribuída a Kant - de conhecer todas as coisas particularmente, o que seria impossível, na sua visão ${ }^{21}$. Essa discussão nos remete ao ca-

\footnotetext{
21 "Atenção aos detalhes mais que à soma de todos os detalhes é o que caracteriza a filosofia científica, na concepção de Nietzsche. Schopenhauer, por outro lado, expressa a existência como tal, em vez de seus detalhes mínimos. Mas esse breve comentário sobre o método de Schopenhauer é também uma descrição do próprio método de Nietzsche [...]. Não é o conteúdo dos livros que é Cont.
} 
pítulo 18 de $\mathrm{O}$ nascimento da tragédia, no qual o autor havia tratado elogiosamente da "vitória" de Kant e de Schopenhauer diante do otimismo que caracterizaria a lógica moderna. Aqui, como se pode perceber, Kant é criticado precisamente por fazer parte do movimento que ele supostamente havia vencido.

O segundo momento de Schopenhauer como educador em que é possível notar uma concepção renovada de metafísica em Nietzsche é a descrição, no capítulo 4, dos três tipos (ou figuras, Bild) de homem que inspiraram os mortais à transfiguração (Verklärung) de suas próprias vidas. Depois de tratar das imagens do homem de Rousseau e de Goethe, Nietzsche se concentra na figura do homem de Schopenhauer. Nesse momento do texto o "homem schopenhaueriano" é entendido como aquele que "toma voluntariamente para si mesmo o sofrimento da veracidade [Leiden der Wahrhaftigkeit]". Este sofrimento, acrescenta Nietzsche, "serve para aniquilar a sua própria obstinação [Eigenwillen] e preparar aquela completa anulação [Umzählung] e conversão [Umkehrung] de sua existência, que deve se seguir do real significado da vida [der eigentliche Sinn des Lebens]" (SE, 4. KSA 1, p. 371. Grifos meus).

A crença do homem da veracidade em um mundo verdadeiro e sem possibilidade de falsificação é o que confere significado à sua atividade metafísica, que é "explicada por meio de leis de uma outra vida, superior, e que é afirmativa no sentido mais profundo" (idem, p. 372). Pelo fato de que

importante: é o caráter do homem que os escreve [...]. Isso significa que, o que quer que nós façamos, o nosso objetivo deve ser ajudar a criar condições favoráveis para a criação do gênio filosófico" (DAHLKVIST 2007, p. 193-4). 
muitas dessas leis parecem ser destrutivas, a sua atividade é necessariamente acompanhada de sofrimento. Mas tal homem sabe que o sofrimento é, como indica Nietzsche por meio de uma citação de Mestre Eckhardt, o mais próximo que há da perfeição. E é com esse ideal que ele conduz a sua vida, consolado pelas "palavras uma vez empregadas pelo seu grande professor, Schopenhauer: 'uma vida feliz é impossível: o máximo que o homem pode obter é uma vida heroica [...]"' (Idem, p. 373).

A noção de vida heroica (heroischer Lebenslauf), descrita por Schopenhauer nos Parerga e Paralipomena (vol. II, cap. $14, \$ 172 \mathrm{a})$ nos termos de um alcançamento da nobreza por meio do nirvana, é retomada aqui por Nietzsche no intuito de descrever a forma com que o homem schopenhaueriano transfigura a sua existência por meio da veracidade e do sofrimento gerado por ela. Se todo homem deseja precisamente cessar de perceber, de estar consciente da vida (dass das Leben [...] nicht gespürt werde), por que deseja o homem schopenhaueriano precisamente o contrário, isto é, "sofrer da vida" (am Leben leiden)? "Porque ele percebe que se deseja que ele engane a si mesmo e que há um tipo de acordo para tirá-lo de sua própria caverna”, ao que ele reage descendo "às profundezas da existência, com uma série de curiosas perguntas nos lábios: por que eu vivo? qual lição devo eu aprender da vida? como eu me tornei como eu sou e por que eu sofro deste ser-assim [So-sein]?” (ibidem, p. 373-4). Como se pode perceber, Nietzsche retoma aqui um tema que lhe foi caro em $\mathrm{O}$ nascimento da tragédia, o da transfiguração, no intuito de tratar de uma forma de vida baseada na busca heroica de sua veracidade. $\mathrm{O}$ autor não o remete, po- 
rém, ao contexto de uma estética, como havia feito em sua primeira publicação.

O terceiro e último momento da terceira Extemporânea em que pode ser localizado esse novo ponto de vista em relação à metafísica é a discussão, no capítulo 5, sobre o significado do sofrimento. Essa discussão se segue àquela acerca da transfiguração da vida pelos três tipos de homem anteriormente mencionados e está em relação, sobretudo, com a descrição do último. Nietzsche se questiona aqui sobre a diferença entre homens e animais, e procura estabelecê-la pela forma com que ambos lidam com o sofrimento. Em um primeiro momento, o autor afirma que os animais sofrem da vida (am Leben leiden), mas não dispõem do poder de "virar o espinho do sofrimento contra si mesmo" e, dessa forma, "entender a sua existência metafisicamente". É por esse motivo, segundo Nietzsche, que se supôs haver escondidas nesses animais "almas de homens carregados de culpa" (Seelen schuldbeladner Menschen), de tal modo que toda punição e expiação se dissolveriam na justiça eterna (ewige Gerechtigkeit) (cf. SE, 5. KSA 1, p. 377).

A impossibilidade de reflexão sobre a dor, isto é, viver na fome e no desejo tal como os animais vivem, seria, de fato, para Nietzsche, uma punição severa. O homem é, então, a única espécie animal que, impelida pelo poder da natureza, desenvolveu a capacidade de se redimir (erlösen) dessa condição, ao atribuir uma significação metafísica (metaphysische Bedeutsamkeit) à existência. $\mathrm{O}$ que diferenciaria homens e animais não seria o fato de desejarem a vida e a alegria, pois ambos o fazem, mas o fato de que os primeiros as buscam de modo mais consciente, enquanto os últimos o 
fazem por um cego impulso.

Nietzsche, entretanto, dá um passo atrás e afirma que o que acontece em grande parte de nossas vidas é viver precisamente como animal (pois falhamos na nossa tentativa de emergir da animalidade) e que, portanto, o nosso sofrimento sempre nos parece sem sentido. Somente percebemos essa situação em uma "iluminação súbita" (plötzliche Helle), na qual nos damos conta de quão próximos da animalidade ainda permanecemos (ibidem, p. 378-9).

Os únicos homens capazes de nos tirar dessa condição de pura animalidade são os filósofos, os artistas e os santos - e Schopenhauer se enquadra em todas essas categorias de homens superiores. A natureza, ao criar tais figuras por um "salto" (springen), "compreende que ela deve desaprender (verlernen) que tenha objetivos (Ziele) e que ela jogou o jogo da vida e do vir a ser (Werden) com apostas muito altas":

Ela se transfigura [verklärt] por meio desse conhecimento e um suave cansaço noturno, que os homens denominam 'a beleza', repousa sobre a sua face. O que ela exprime agora com essa fisionomia transfigurada é o grande esclarecimento [Aufklärung] sobre a existência; e o supremo desejo que os mortais podem desejar é participar, continuamente e com ouvidos abertos, desse esclarecimento [...]. Pois como a natureza necessita do filósofo, do mesmo modo ela necessita do artista para atingir o seu alvo metafísico, aquele de seu próprio autoesclarecimento (SE, 5. KSA 1, p. 380-2).

Após levar em consideração essas três questões, esperase poder tornar mais claras as razões pelas quais a metafísica - e, nesse momento do pensamento de Nietzsche, a filosofia - passa a ser compreendida como "visão de mundo", que favorece a formação de determinados tipos de homem de excelência e que atribui sentido à existência, e não como 
uma busca pela essência íntima do universo e uma tentativa de justificação da existência por meio da arte, tal como o autor havia sugerido em $\mathrm{O}$ nascimento da tragédia.

A figura que se sobressai na suposta apologia que $\mathrm{Ni}$ etzsche faz de Schopenhauer é, entretanto, Montaigne, a quem o autor se dirige de modo tão elogioso que causa certo espanto, dado o caráter do texto:

Que haja algo chamado honestidade [Ehrlichkeit], e que seja ainda uma virtude, pertence, sem dúvida, na idade da opinião pública às opiniões privadas, as quais são proibidas; e, por isso, eu não terei elogiado Schopenhauer, mas somente o caracterizado, caso eu repita: ele é honesto também como escritor; e tão poucos escritores são honestos que alguém deveria realmente desconfiar de alguém que escreve. Eu conheço somente um único escritor que eu comparo com Schopenhauer, na verdade o coloco acima dele, em matéria de honestidade: Montaigne. Aquilo que tal homem escreveu verdadeiramente aumentou o prazer de viver sobre a terra (SE, 2. KSA 1, p. 348).

Otom com que Nietzsche descreve o pensador francês continua o mesmo nas linhas que se seguem. $O$ autor enumera ainda uma segunda característica que Schopenhauer e Montaigne teriam em comum, a jovialidade (Heiterkeit ${ }^{22}$. Esta demonstraria a sabedoria de que ambos compartilham: "Aliis laetus, sibi sapiens" ("divertido para os outros, sábio para si mesmo"). É essa jovialidade do "verdadeiro pensador" (wahrer Denker) que os permite divertir com seus escritos, independentemente do conteúdo de que tratam, e que os torna seguros, simples, corajosos e fortes; ao contrário, por

\footnotetext{
${ }^{22} \mathrm{O}$ termo alemão Heiterkeit pode ser traduzido como alegria, hilaridade, diversão, mas também como jovialidade, como sugere o tradutor brasileiro de O nascimento da tragédia, ao vertê-lo como "serenojovialidade".
} 
exemplo, de Strauss, de cuja jovialidade Nietzsche dizia se sentir envergonhado: tal tipo de pensador é aquele que "não vê de modo algum os sofrimentos e dissabores que ele finge ver e combater" (SE, 2. KSA 1, p. 349).

De uma série de intérpretes que tratam da relação de Nietzsche com os autores franceses, William David Williams é aquele que, em um dos textos clássicos sobre o assunto, defende uma tese bastante precisa acerca desse momento em que Schopenhauer e Montaigne são contrastados no pensamento do autor. Segundo ele, "a profunda convicção de Montaigne acerca do supremo valor e prazer de existir é precisamente o oposto à visão schopenhaueriana de que a nossa única conquista vantajosa na vida é a minimização da dor" (WILLIAMS, 1952, p. 33). Isso não quer dizer, contudo, que Nietzsche esteja tomando Montaigne como uma forma de repúdio a Schopenhauer, mas que o pensador francês lhe serve como uma possibilidade de pensar a vida sob outra perspectiva, a qual o autor foi se inclinando cada vez mais: "após os anos anteriores, poder-se-ia dizer que Nietzsche se coloca a tarefa de encontrar uma resposta ao pessimismo de Schopenhauer - ele tinha que se 'acertar com' ele, do mesmo modo que teve que se 'acertar com' o cristianismo - e Montaigne é talvez o seu maior aliado nessa tarefa" ${ }^{23}$.

\footnotetext{
${ }^{23}$ Uma posição semelhante a de Williams sobre o papel da Heiterkeit de Montaigne no pensamento de Nietzsche, sobretudo no período de Schopenhauer como educador, é defendida por DIETZSCH (1994).

E, de modo semelhante a Williams, considera que o pensador francês exerce um fascínio oposto ao de Schopenhauer, ainda que Nietzsche não adote o pensamento do primeiro em detrimento do segundo: "Schopenhauer continua sendo instrutivo, mas já não mais na condição de alguém que aponta para o futuro, ou que nos esclarece sobre as necessidades do presente; nem tampouco na qualidade de um grande liberador. Ele é instrutivo apenas na medida em que abre para o filóCont.
} 
Para Rogério Lopes, a inserção de Montaigne em Schopenhauer como educador é o indício de que o entusiasmo de Nietzsche pelo filósofo de Danzig não é incondicional, dado que o texto foi escrito "em um momento em que Nietzsche já não compartilhava nenhuma das teses metafísicas de seu grande educador" (LOPES, 2008, p. 324). O motivo pelo qual ele não toma Montaigne como o educador do título da Extemporânea é, segundo o autor, o fato de que Nietzsche ainda estava apegado, naquele momento de sua produção, à "tese da inevitabilidade antropológica da metafísica" - com a qual ele virá a romper apenas com a publicação do primeiro volume de Humano, demasiado humano (idem, cf. p. 289 e 37). Esta tese de Lopes talvez nos dê um bom ensejo não para uma afirmação conclusiva sobre o estatuto da metafísica em Schopenhauer como educador, o que não é o objetivo do presente texto, mas para que se possa compreender melhor o processo que se empreendeu demonstrar desde o seu início: o de que o estatuto da metafísica é alvo das críticas de Nietzsche desde os primeiros anos de sua produção filosófica e, além disso, de que os ecos dessas críticas se fazem presentes já no primeiro período de sua obra publicada, e não apenas em suas anotações pessoais. A concepção de filosofia como "visão de mundo" é, tal como se pretendeu mostrar a partir de seus questionamentos à metafísica schopenhaueriana, uma clara evidência de o posicionamento do autor

\footnotetext{
sofo uma via para o conhecimento do passado. Através dele, e em grande medida à sua revelia, pode-se fazer justiça a este passado e corrigir uma leviandade do século das Luzes. [...]. Montaigne é o grande liberador. Ele aponta para a possibilidade de uma vida indiferente às seduções do ideal ascético. E ele o faz contra o pano de fundo de um ceticismo que, tal como o de Nietzsche, tem uma inegável motivação ontológica" (cf. LOPES, op. cit., p. 324-6. As citações anteriores foram retiradas das páginas 324 e 326, respectivamente).
} 
acerca do tema já se altera sensivelmente no interior de sua obra de juventude.

Abstract: This paper has its focus on the discussion of some key aspects of Nietzsche's critique to metaphysics, already in his first philosophical reflections. With this aim, some of his main arguments against the establishment of the will as the thing in itself by Arthur Schopenhauer's thought (and, therefore, against the statute of metaphysics in this philosophy) will be analyzed, in such a way that one can demonstrate the solutions, found by the author himself, in favor of the possibility of metaphysics. That way, the paper still aims to contribute to the discussions about the relationship between private reflections and published texts by the German philosopher, as far as it holds the thesis according which from an analysis of Nietzsche's critique to metaphysics in his private notes one can understand the seeds of why he changes his approach on it in his published books.

Keywords: Nietzsche; Schopenhauer; metaphysics.

\section{REFERÊNCIAS}

BARBERA, S. Ein Sinn und unzählige Hieroglyphen. Einige Motive von Nietzsches Auseinandersetzung mit Schopenhauer in der Basler Zeit. In: BORSCHE, T. (hrsg.) 'Centauren-Geburten': Wissenschaft, Kunst und Philosophie beim jungen Nietzsche. Berlin/New York: de Gruyter, 1994, pp. 217-33.

- Eine Quelle der frühen Schopenhauer-Kritik Nietzsches: Rudolf Hayms Aufsatz 'Arthur Schopenhaer'. Nietzsche-Studien 24 (1995), 124-36.

. Um sentido e incontáveis hieróglifos. Alguns motivos da polêmica de Nietzsche com Schopenhauer nos tempos de Leipzig e da Basileia. Cadernos Nietzsche 27, 2010, p. 13-50.

BROBJER, T. Nietzsche as German philosopher. In: 
MARTIN, N. Nietzsche and the German tradition. Bern: Peter Lang Publishing, 2003, pp. 40-82.

BROESE, K. Nietzsches erste Begegnung mit Schopenhauer im Lichte eines bisher unveröffentlichten Manuskriptes aus seiner Bonner Studienzeit. Schopenhauer-Jahrbuch 85 (2004), 13-26.

. Nietzsches frühe Auseinandersetzung mit Kants Kritizismus. In: HIMMELMANN, B. (Hrsg.). Kant und Nietzsche im Widerstreit. Berlin / New York, 2005, pp. 363-372.

CLARK, M. Nietzsche: on truth and philosophy. New York: Cambridge University Press, 1994.

CRAWFORD, C. The Beginning of Nietzsche.s Theory of Language. Berlin: de Gruyter, 1988.

DAHLKVIST, T. Nietzsche and the Philosophy of Pessimism. A study of Nietzsche's Relation to the Pessimistic Tradition: Schopenhauer, Hartmann, Leopardi. Uppsala: Uppsala Studies in History of Ideas 35, 2007.

DECHER, F. Nietzsches Metaphysik in der "Geburt der Tragödie" im Verhältnis zur Philosophie Schopenhauers. Nietzsche-Studien 14 (1985), 110-125.

DIETZSCH, S. Montaigne und Nietzsche - die Kunst des Lachens. Nietzscheforschung 1 (1994), 65-68.

FIGL, J. Nietzsches Begegnung mit Schopenhauers Hauptwerk. Unter Heranziehung eines frühen unveröffentlichen Exzerptes. Schopenhauer-Studien 4 (1991), 89-110. 
FLEISCHER, M. Dionysus als Ding an sich. Der Anfang von Nietzsches Philosophie in der ästhetischen Metaphysik der "Geburt der Tragödie". Nietzsche-Studien 17 (1988), $74-90$.

HOUlGATE, S. Kant, Nietzsche and the thing in itself. NSt. 22 (1993). Frankfurt am Main: Suhrkamp, 1984. Pp. 253-62.

JANZ, C. P. Friedrich Nietzsche. Versión española de Jacob Muñoz. Madrid: Alianza Editorial, 1987.

KANT, I. Crítica da razão pura. Tradução de Manuela Pinto dos Santos e Alexandre Fradique Morujão. Lisboa: Fundação Calouste Gulbenkian, 2008.

LOPES, R. A. Ceticismo e vida contemplativa em Nietzsche. FAFICH-UFMG, Tese de Doutorado, 2008.

NIETZSCHE, F. Além do bem e do mal: prelúdio a uma filosofia do futuro. Tradução de Paulo Cezar de Souza. São Paulo: Companhia das Letras, 2005.

- Crepúsculo dos ídolos ou como se filosofa com o martelo. Tradução de Paulo César de Souza. São Paulo: Companhia das Letras, 2006.

- O nascimento da tragédia: ou Helenismo e Pessimismo. Tradução de J. Guinsburg. São Paulo: Companhia das Letras, 1992.

- Sämtliche Werke. Kritische Studienausgabe (KSA: 15 vols.). Hrsg. von G. Colli und M. Montinari. Berlin/New York: de Gruyter, 1988.

. Sämtliche Briefe. Kritische Studienausgabe (KSB: 
08 vols.). Hrsg. von G. Colli und M. Montinari. Berlin/New York: de Gruyter, 1986.

. Werke. Kritische Gesamtausgabe (KGW: 40 vols. (ainda em andamento) Hrsg. von G. Colli und M. Montinari, weitergeführt von W. Müller-Lauter und K. Pestalozzi. Berlin/New York: Walter de Gruyter, $1963 \mathrm{ff}$.

PORTER, J. The invention of Dionysus: an essay on The birth of tragedy. Standford/California: Standford University Press, 2000.

RICCARDI, M. Nietzsche's Critique of Kant's Thing in Itself. NSt. 39 (2010), 333-351.

SCHOPENHAUER, A. O mundo como vontade e como representação. Tradução de Jair Barboza. São Paulo: UNESP, 2005.

. Sämtliche Werke. Textkritisch bearbeitet und herausgegeben von Wolfgang Frhr. von Löhneysen. Stuttgart/Frankfurt am Main: Suhrkamp, 1986.

- Sämtliche Werke. Herausgegebenen von Paul Deussen. München: Piper Verlag, 1911-1926, Bd. I-VI (Versão em CD-ROM: "Schopenhauer im Kontext").

SCHLECHTA, K. Der junge Nietzsche und Schopenhauer. Schopenhauer-Jahrbuch 26 (1939), 289300.

SPIERLING, V. (Hrsg.) Materielen zu Schopenahuers ,Die Welt als Wille und Vorstellung'. Frankfurt am Main: Suhrkamp Taschenbuch Verlag, 1984.

WILLIAMS, W. D. Nietzsche and the French. Oxford: 
Wander de Paula

Basil Blackwell, 1952. 